\title{
The Human Equilibrative Nucleoside Transporter Protein1 (Hent1) is a Predict /Prognostic Factor in Resected Pancreatic Cancer Patients
}

\author{
Zhao Hongbing ${ }^{1}$, Zhang Xifeng ${ }^{2}$, Wang Jingjing ${ }^{1}$ and Li XiaoRui ${ }^{1 *}$ \\ ${ }^{1}$ Department of Oncology, First Affiliated Hospital of Xinxiang Medical College, China \\ ${ }^{2}$ ShangQiu Medical School, Shang Qiu, China
}

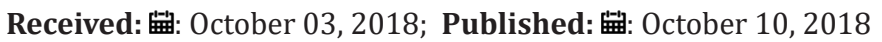

*Corresponding author: Li Xiao Rui, Department of Oncology, First Affiliated Hospital of Xinxiang Medical College, Xinxiang, Henan, China

\begin{abstract}
Pancreatic cancer is currently one of the deadliest of the solid malignancies and has a particularly low survival rate in the future because targeted therapies for other cancers are becoming more advanced than those for pancreatic cancer [1]. The optimal treatment first and foremost depends on careful accurate staging. The American Joint Committee on Cancer (AJCC) staging system, which includes the TNM classification, is the most widely used system to stage pancreatic cancer [2]. Patients with Stage I/II disease should undergo surgical resection followed by adjuvant therapy, while patients with Stage III borderline resectable cancers should undergo neoadjuvant therapy prior to resection. Patients with stage III locally advanced disease should be treated with chemotherapy and/or chemoradiotherapy. Patients with Stage IV and good performance status may receive systemic therapy and those with poor overall health should be given supportive therapy [3].
\end{abstract}

\section{Introduction}

A meta-analysis of trials performed between 1970 and 2003 demonstrated that 5-FU was superior to best supportive care [4]. But in 1997 a randomized phase III trial demonstrated a survival benefit for gemcitabine over bolus 5-FU with a median survival of 5.65 months as compared to 4.41 months, and 1-year survivals of $18 \%$ versus $2 \%$. Gemcitabine had a superior clinical benefit response described as improvement in pain, performance status or weight in $24 \%$ of the patients versus $5 \%$ in the 5 -FU group. Based on this trial, gemcitabine was approved by the Food and Drug Administration for pancreatic cancer and gemcitabine became the standard of care [5]. From then on, a lot of gemcitabine-based combinations have been tested [6]. Gemcitabine plus oxaliplatin or cisplatin showed no statistically significant improvement in survival in phase III trials [7-8]. A phase I/II trial published in 2011 demonstrated exciting results when gemcitabine was combined with nab-paclitaxel as first-line therapy for metastatic pancreatic cancer patients [9]. Gemcitabine has also been tested in combination with several different targeted therapies. A phase III randomized trial demonstrated a statistically significant improvement in overall survival from 5.91 months with single-agent gemcitabine to 6.24 months with gemcitabine plus erlotinib [10]. FOLFIRINOX was initially described in France as oxaliplatin $85 \mathrm{mg} / \mathrm{m} 2$, leucovorin $400 \mathrm{mg} / \mathrm{m} 2$, irinotecan $180 \mathrm{mg} / \mathrm{m} 2,5-\mathrm{FU}$ bolus $400 \mathrm{mg} / \mathrm{m} 2$ on day 1 followed by a 46 -hour continuous infusion of 5 -FU $(2400 \mathrm{mg} / \mathrm{m} 2)$ repeated every 2 weeks and has been recommended as an option for first-line therapy in patients with a good performance status [11]. Second-line treatment is not very well established, partially because many of the patients are not strong enough to undergo further treatment. So, gemcitabine is a basement agent for the treatment of pancreatic cancer.

Gemcitabine belongs to one of the nucleoside-derived analog drugs and hENT1 is generally considered to be predominantly involved in gemcitabine transport. Human equilibrative nucleoside transporter protein1 (hENT1, SLC29A1), the first identified member of the human SLC29 family in 1997, [12] is a primary transmembrane protein for the intracellular uptake of the prodrug gemcitabine into tumor cells [13]. Glycosylation is involved in functional property of hENT1 protein and may play key roles in substrate recognition. S-(4-Nitrobenzyl)-6-thioinosine (NBTI, NBMPR) is a small molecule inhibitor of hENT1, it can effectively inhibit the cellular uptake and/or efflux of physiologic nucleosides and many anti-cancer nucleoside analogs, so hENT1 can be divided into NBMPR-sensitive (es) and NBMPR-insensitive (ei). During the decade, the hypothesis that hENT1 overexpression might serve as a predictive biomarker for the efficacy of gemcitabine has been demonstrated by some pre-clinical studies and clinical investigations [14-16]. In a series of 105 patients with pancreatic cancer treated with gemcitabine, higher hENT1 levels were 
associated with a significant longer median Overall Survival (OS) (25.69 vs 8.49 months) and median Disease-Free Survival (20.43 vs 9.26 months).

The multivariate analysis confirmed hENT1 expression as an independent factor associated with survival [17]. In RTOG9704, 538 patients were assigned randomly, after surgical resection, to groups that were given either gemcitabine or 5-fluorouracil (5-FU). hENT1 expression was associated with overall and disease-free survival in a univariate and multivariate model in the group given gemcitabine but was not associated with survival in the group given 5-FU [15].
In patients randomly assigned to gemcitabine, 35.2\% (126/358) of patients with metastatic pancreatic ductal adenocarcinoma were hENT1 high, there was no difference in survival between the high and low hENT1 subgroups (HR, 1.147; 95\% CI, 0.809 to 1.626 ). This is surprising because previous reports have demonstrated a strong relationship between tumor hENT1 expression and gemcitabine outcome. Up to now, the predictive value of hENT1 in pancreatic cancer therapy is a controversial issue. The relationship between high hENT1 expression and survival in pancreatic cancer samples is in (Table 1) [18-25].

Table 1: the relationship between high hENT1 expression and survival in pancreatic cancer samples.

\begin{tabular}{|c|c|c|c|c|}
\hline Reference & Total no. of Patients & hENT1 positive rate (\%) & Patients & Results \\
\hline Sinn et al. [19] & 88 & 32 & resection & $\begin{array}{c}\text { High levels of hENT1 was not associated with } \\
\text { improved median DFS }\end{array}$ \\
\hline Maréchal et al. [20] & 234 & 39.3 & resection & $\begin{array}{c}\text { High levels of hENT1 have a significantly } \\
\text { longer survival }\end{array}$ \\
\hline Marechal et al. [21] & 45 & 42 & resection & $\begin{array}{c}\text { gemcitabine should not be used for patients } \\
\text { with low tumor hENT1 expression }\end{array}$ \\
\hline Greenhalf et al. [22] & 176 & 56.3 & resection & $\begin{array}{c}\text { High levels of hENT1 was significantly } \\
\text { associated with a longer survival }\end{array}$ \\
\hline Morinaga et al. [23] & 27 & 59 & resection & HENT1 is an independent prognostic factor \\
\hline Nakagawa et al. [24] & 109 & 71.6 & $\begin{array}{c}\text { hesection } \\
\text { renT1 is a molecular and mechanistically } \\
\text { relevant predictive marker }\end{array}$ \\
\hline Farrel et al. [15] & 91 & 80 & $\begin{array}{c}\text { previously } \\
\text { untreated }\end{array}$ & $\begin{array}{c}\text { there was no difference in survival between } \\
\text { the high and low hENT1 subgroups }\end{array}$ \\
\hline Poplin et al. [25] & 358 & 35.2 & & \\
\hline
\end{tabular}

\section{Conclusion}

In conclusion, we found that tumor hENT1 level predicts clinical outcome when undergoing adjuvant gemcitabine-based chemotherapy for resected pancreatic cancer patients. Due to the difficulty of early diagnosis, only $20 \%$ of patients with pancreatic cancer are considered surgical resectable, other $80 \%$ patients remain to be chemotherapy or radiotherapy or palliative care [26]. The predictive value of hENT1 in previously untreated pancreatic cancer patients still need to be investigated via larger series, preferably within a prospective trial or randomized controlled trial. Low chemosensitivity considerably restricts the therapeutic efficacy of gemcitabine in pancreatic cancer treatment. The process of cellular uptake and intracellular metabolism of gemcitabine in cancer cells is complex, and many factors affect gemcitabine cytotoxicity. Therefore, the combined expression analysis of hENT1 with other markers could contribute to a beneficial clinical outcome.

\section{References}

1. Flemming A (2016) Cancer: Engineered T cells gain access to pancreatic tumours. J Nat Rev Drug Discov 15(1): 16-17.

2. American Joint Committee on C (2010) AJCC cancer staging handbook. Vol 8. New York: Springer-Verlag.

3. Varadhachary GR, Wolff RA, Crane CH, Sun CC, Lee JE, et al. (2008) Preoperative gemcitabine-based chemoradiation for patients with resectable adenocarcinoma of the pancreatic head. J Clin Oncol 26(21): 3487-3495.
4. Fung MC, Takayama S, Ishiguro H, Sakata T, Adachi S, et al. (2003) Chemotherapy for advanced or metastatic pancreatic cancer: analysis of 43 randomized trials in 3 decades (1974-2002). J Gan To Kagaku Ryoho 30(8): 1101-1111.

5. Burris HA, Moore MJ, Andersen J, Green MR, Rothenberg ML, et al. (1997) Improvements in survival and clinical benefit with gemcitabine as firstline therapy for patients with advanced pancreas cancer: a randomized trial. J Clin Oncol 15(6): 2403-2413.

6. Sultana A, Smith CT, Cunningham D, Starling N, Neoptolemos JP, et al. (2007) Meta-analyses of chemotherapy for locally advanced and metastatic pancreatic cancer. J Clin Onco 25(18): 2607-2615.

7. Louvet C, Labianca R, Hammel P, Lledo G, Zampino MG, et al. (2005) Gemcitabine in combination with oxaliplatin compared with gemcitabine alone in locally advanced or metastatic pancreatic cancer: results of a GERCOR and GISCAD phase III trial. J Clin Oncol 23(15): 3509-3516.

8. Colucci G, Labianca R, Di Costanzo F, Gebbia V, Cartenì G, et al. (2010) Randomized phase III trial of gemcitabine plus cisplatin compared with single-agent gemcitabine as first-line treatment of patients with advanced pancreatic cancer: the GIP-1 study. J Clin Oncol 28(10): 16451651.

9. Von Hoff DD, Ramanathan RK, Borad MJ, Laheru DA, Smith LS, et al. (2011) Gemcitabine plus nab-paclitaxel is an active regimen in patients with advanced pancreatic cancer: a phase I/II trial. J Clin Oncol 29(34): $4548-4554$

10. Moore MJ, Goldstein D, Hamm J, Figer A, Hecht JR, et al. (2007) Erlotinib plus gemcitabine compared with gemcitabine alone in patients with advanced pancreatic cancer: a phase III trial of the National Cancer Institute of Canada Clinical Trials Group. J Clin Oncol 25(15): 1960-1966. 
11. Conroy T, Desseigne F, Ychou M, Bouché O, Guimbaud R, et al. (2011) FOLFIRINOX versus gemcitabine for metastatic pancreatic cancer. N Engl J Med 364(19): 1817-1825.

12. Yao SY, Ng AM, Muzyka WR, Griffiths M, Cass CE, et al. (1997) Molecular cloning and functional characterization of nitrobenzylthioinosine (NBMPR)-sensitive (es) and NBMPR-insensitive (ei) equilibrative nucleoside transporter proteins (rENT1 and rENT2) from rat tissues. J Biol Chem 272(45): 28423-28430.

13. Ueno H, Kiyosawa K, Kaniwa N (2007) Pharmacogenomics of gemcitabine: can genetic studies lead to tailor-made therapy? $\mathrm{Br}$ Cancer 97(2): 145-151.

14. Michalski CW, Erkan M, Sauliunaite D, T Giese, R Stratmann, et al. (2008) Ex vivo chemosensitivity testing and gene expression profiling predict response towards adjuvant gemcitabine treatment in pancreatic cancer. Br J Cancer 99(5): 760-767.

15. Farrell JJ, Elsaleh H, Garcia M, Lai R, Ammar A, et al. (2009) Human equilibrative nucleoside transporter 1 levels predict response to gemcitabine in patients with pancreatic cancer. Gastroenterology 136(1): 187-195.

16. Vincenzi B, Stacchiotti S, Collini P, Pantano F, Rabitti C, et al. (2017) Human equilibrative nucleoside transporter 1 gene expression is associated with gemcitabine efficacy in advanced leiomyosarcoma and angiosarcoma. Br J Cancer 117(3): 340-346.

17. Giovannetti E, Del Tacca M, Mey V, Funel N, Nannizzi S, et al. (2006) Transcription analysis of human equilibrative nucleoside transporter-1 predicts survival in pancreas cancer patients treated with gemcitabine. Cancer Res 66(7): 3928-3935.

18. Bird NT, Elmasry M, Jones R, Psarelli E, Dodd J, et al. (2017) Immunohistochemical hENT1 expression as a prognostic biomarker in patients with resected pancreatic ductal adenocarcinoma undergoing adjuvant gemcitabine-based chemotherapy. Br J Surg 104(4): 328-336.

19. Sinn M, Riess H, Sinn BV, Stieler JM, Pelzer U, et al. (2015) Human equilibrative nucleoside transporter 1 expression analysed by the clone

\section{ISSN: 2574-1241}

DOI: $10.26717 / B J S T R .2018 .09 .001860$

Li XiaoRui. Biomed J Sci \& Tech Res

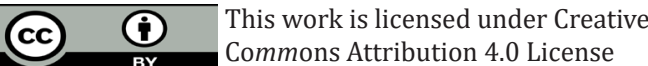

Submission Link: https://biomedres.us/submit-manuscript.php
SP 120 rabbit antibody is not predictive in patients with pancreatic cancer treated with adjuvant gemcitabine - Results from the CONKO-001 trial. Eur J Cancer 51(12): 1546-1554.

20. Maréchal R, Bachet JB, Mackey JR, Dalban C, Demetter P, et al. (2012) Levels of gemcitabine transport and metabolism proteins predict survival times of patients treated with gemcitabine for pancreatic adenocarcinoma. Gastroenterology 143(3): 664-674.

21. Maréchal R, Mackey JR, Lai R, Demetter P, Peeters M, et al. (2009) Human Equilibrative NucleosideTransporter 1and Human Concentrative NucleosideTransporter 3 Predict Survival after Adjuvant GemcitabineTherapyi n Resected Pancreatic Adenocarcinoma. Gastroenterology 15(8): 2913-2919.

22. Greenhalf W, Ghaneh P, Neoptolemos JP, Palmer DH, Cox TF, et al. (2014) Pancreatic cancer hENT1 expression and survival from gemcitabine in patients from the ESPAC-3 trial. J Natl Cancer Inst 106(1): 347.

23. Morinaga S, Nakamura Y, Watanabe T, Mikayama $H$, Tamagawa $H$, et al. (2012) Immunohistochemical Analysis of Human Equilibrative Nucleoside Transporter-1 (hENT1) Predicts Survival in Resected Pancreatic Cancer Patients Treated with Adjuvant Gemcitabine Monotherapy. Ann Surg Oncol 19 (Suppl 3): S558-564.

24. Nakagawa N, Murakami Y, Uemura K, Sudo T, Hashimoto Y, et al. (2013) Combined analysis of intratumoral human equilibrative nucleoside transporter 1 (hENT1) and ribonucleotide reductase regulatory subunit M1 (RRM1) expression is a powerful predictor of survival in patients with pancreatic carcinoma treated with adjuvant gemcitabine-based chemotherapy after operative resection. Surgery 153(4): 565-575

25. Poplin E, Wasan H, Rolfe L, Ikdahl T, Bondarenko I, et al. (2013) Randomized, Multicenter, Phase II Study of CO-101 Versus Gemcitabine in Patients with Metastatic Pancreatic Ductal Adenocarcinoma: Including a Prospective Evaluation of the Role of hENT1 in Gemcitabine or CO-101 Sensitivity. J Clin Oncol 31(35): 4453-4461.

26. Ryan DP, Hong TS, Bardeesy N (2014) Pancreatic adenocarcinoma. N Engl J Med 371(22): 2140-2141.

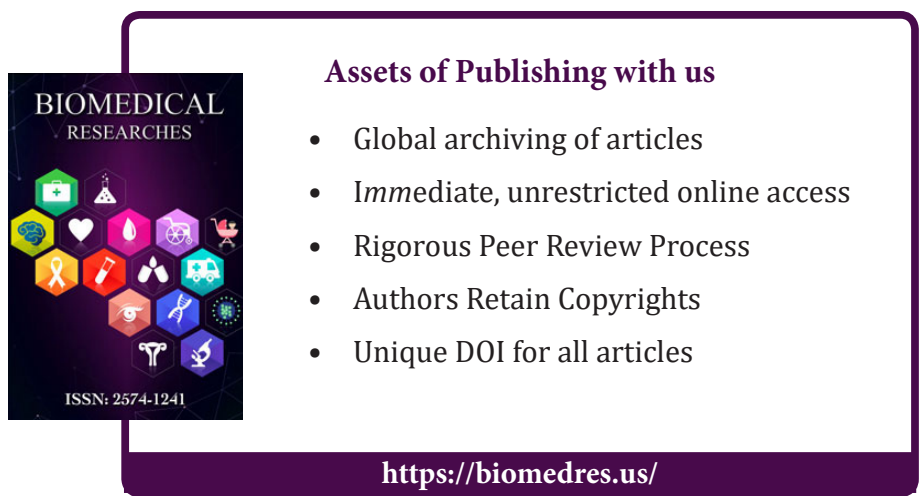

